\title{
AGE-PERIOD-COHORT ANALYSIS OF MOTOR VEHICLE MORTALITY IN TAIWAN, 1974-1992
}

\author{
JAU-YIH TSAUO $^{1}$, Wen-Chung LeE ${ }^{2}$ and Jung-Der WANG ${ }^{1}{ }^{*}$
}

\begin{abstract}
${ }^{1}$ Center for Research of Environmental and Occupational Diseases, Institute of Occupational Medicine and Industrial Hygiene; ${ }^{2}$ Graduate Institute of Epidemiology, National Taiwan University, College of Public Health No. 1, Sec. 1, Jen-Ai Rd, Taipei, Taiwan, R.O.C. 10016
\end{abstract}

(Received 4 March 1995; accepted 1 April 1996)

\begin{abstract}
The aim of this study was to examine the effects of age, calendar period of death and birth cohort in motor vehicle mortality in Taiwan over the period 1974-1992. A log-linear model modified from the method of Osmond and Gardner (Stat. Med. 1: 245-259; 1982) was used. Age turned out to be a significant predictor of motor vehicle mortality. The most risky group (over 70 years) had 27.1 and 16.3 times the mortality of the least risky group (5-9 years, 10-14 years) for males and females respectively. The period effect showed a continuously increasing mortality trend since 1974 in females. The pattern in males is similar except that it has slightly leveled off in recent years. The birth cohorts at the highest risk of motor vehicle death were those born between 1979 and 1983 for both sexes. However, males born between 1929 and 1933 also had a high mortality. This analysis provided a better understanding of the trend of mortality from motor vehicle crashes. Copyright (C) 1996 Elsevier Science Ltd
\end{abstract}

Keywords-Age-period-cohort analysis, Mortality rate, Motor vehicle mortality, Temporal trend

\section{INTRODUCTION}

Mortality from motor vehicle crashes is still a serious public health problem in both developing and developed countries (Bangdiwala et al. 1990; Grisso et al. 1991; Langley and McLoughlin 1989; Rockett and Smith 1989). Older drivers are often found to have a higher mortality rate (Baker et al. 1992; Li and Baker 1991). This is also true in Taiwan (Chen et al. 1993). Nevertheless, it is still unclear whether it is a pure age effect, an effect due to different calendar periods, or an effect of the birth cohorts. This problem has been touched upon in a recent study (Evans 1993), which, however, only considers the three temporal variables separately. The three effects due to age, period and cohort may have different implications for motor vehicle crashes. For example, a (pure) age effect of excessive old-age mortality underlines the importance of biological susceptibility in the elderly. A period effect of a sharp decline of mortality after a particular year may be the hallmark of the success of a public health intervention program. The presence of a cohort effect raises the possibility that different cultural and/or social environments experienced by different birth-cohorts may have a role in motor

\footnotetext{
*Author for correspondence.
}

vehicle mortality. In this study, we apply the ageperiod-cohort (APC) model to analyze mortality data from motor vehicle crashes from 1974 to 1992 in Taiwan. This APC model enables us to better characterize these temporal factors in a unified framework.

\section{MATERIALS AND METHOD}

Deaths from motor vehicle crashes (ICD code E810-819) (World Health Organization 1975) by age and sex from 1974 to 1992 and the corresponding population sizes in the Taiwan area were abstracted from the Vital Statistics published by the Department of Health, Executive Yuan (1974-1992). Cumulative mortality rates $\left(\mathrm{CMR}_{0-74}\right)$ for both sexes were calculated from birth to 74 years old, which can be expressed as

$$
1-\exp \left[-\sum_{0}^{74} M R_{i}^{*} \Delta t_{i}\right]
$$

where $M R_{i}$ is the average mortality rate for age stratum $i$ and $\Delta t_{i}$ is the interval of age stratum $i$.

$\mathrm{CMR}_{0-74}$ represents the risk of death during the age period of $0-74$ years old from motor vehicle crashes under the assumption of no competing causes of death (Rothman 1986). Because it is a summary measure for cross-sectional information of a particular 
year and may not represent the true temporal trend for different cohorts born in different periods of time throughout the decades, we have further analysed the risk by the APC model.

The APC model assumes a log-linear form for the mortality from motor vehicle crashes, that is, $\log \lambda_{i j}=\mu+\alpha_{i}+\beta_{j}+\gamma_{k}, k=j-i+I$, where the $\lambda_{i j}$ represents the unknown true mortality of motor vehicle crashes which is cross-classified by age (indexed by $i$, $i=1,2,3, \ldots, I$ ) and period (indexed by $j, j=1,2,3$, $\ldots, J)$. The $\mu$ is a constant term representing the 'grand mean' of the $(\log )$ mortality. The parameters of $\alpha_{i}, \beta_{j}$ and $\gamma_{k}$ represent the effects due to age, period and cohort respectively. Usually, a reference group for each of the three temporal variables is chosen and the corresponding parameter is set to zero. The exponentials of the parameters $\left(\exp \left(\alpha_{i}\right), \exp \left(\beta_{j}\right), \exp \left(\lambda_{k}\right)\right)$ are then interpreted as the (adjusted) 'relative risks' for the age, period and cohort variables respectively. In this paper, we use the constraint

$$
\sum_{i} \alpha_{i}=\sum_{j} \beta_{j}=\sum_{k} \gamma_{k}=0
$$

instead. The exponentials of the parameters under this constraint can also be interpreted as the 'relative risks', though the reference groups are not explicitly defined. The equation of ' $k=j-i+I$ ' states the fact that the indices of $i$ (for age effects), $j$ (for periods effects) and $k$ (for cohort effects) are not independent. That is, knowledge of a subject's age and of the calendar year his/her death occured implies logically the subject's birth year. The relation creates an identifiability problem for the APC model such that a unique set of parameters can not be obtained without the imposing of an additional constraint besides the usual constraint described above. We use the constraint introduced by Osmond and Gardner (1982) to cope with the identifiability problem. In brief, the estimates were derived from the APC model, including the three factors (age, period and cohort). That minimizes the weighted sum of the Euclidean distance from the three possible two-factor models (age/period, age/cohort, period/cohort). The weights used in the minimization process were based on the goodness-offit of each two-factor model. In this study, these were taken as the inverse of the deviance statistics. To date, there have been several approaches being put forth to 'solve' the identifiability problem inherent in the APC model, including ours (Lee and Lin 1995, 1996a,b). Some of the constraints in these approaches have been criticized for their arbitrariness and for lacking a biologically sound rationale (Holford 1991). We adopted the approach of Osmond and Gardner since we feel that the biological or social basis for motor vehicle crashes is still cloudy at present and therefore letting the 'data-driven' constraint to help locate the relevant parameters may be a reasonable approach.

The actual calculation involves the matrices of the age-specific death rates from motor vehicle crashes for each five year period (from 1974-1978 to 1989-1992) and each age group $(0-4,5-9, \ldots, 65-69$, $70+$ ), from which 15 age groups, 4 period groups and 18 cohort groups are defined. A computer program which has previously been applied to the analysis of lung cancer and luberculosis mortality in Taiwan (Lee et al. 1994a,b), written in the SAS/IML language (SAS Institute Inc. 1988), has been developed to perform the calculations.

\section{RESULTS}

The $\mathrm{CMR}_{0-74}$ from motor vehicle crashes for males and females in Taiwan from 1974 to 1992 are shown in Table 1 . The $0-74$ years CMR increased from 0.028 and 0.008 to 0.046 and 0.016 for males and females respectively. The sex ratios of $\mathrm{CMR}_{0-74}$ (male/female) decreased from 3.41 to 2.91 during this period.

Age-specific mortality rates are tabulated in Tables 2 and 3 for males and females respectively. We have found that the mortality rates increase with age. An early peak in young adolescence of 15-19 and 20-24 for each sex can also be noticed. In addition, the rates increase in most calendar years.

Mortality rates against birth cohorts are presented in Fig. 1(A) for males and Fig. 1(B) for females respectively. The figures show that the general trend

Table 1. Cumulative mortality rates $(0-74$ years of age) and the ratio for both sexes of motor vehicle crashes in Taiwan from 1974 to 1992

\begin{tabular}{lccc}
\hline & Male & Female & M/F ratio \\
\hline 1974 & 0.02822 & 0.00827 & 3.41 \\
1975 & 0.02927 & 0.00908 & 3.22 \\
1976 & 0.03176 & 0.00997 & 3.19 \\
1977 & 0.03500 & 0.01137 & 3.08 \\
1978 & 0.03937 & 0.01265 & 3.11 \\
1979 & 0.04310 & 0.01409 & 3.06 \\
1980 & 0.04493 & 0.01455 & 3.11 \\
1981 & 0.04311 & 0.01545 & 2.79 \\
1982 & 0.04166 & 0.01396 & 2.98 \\
1983 & 0.04069 & 0.01443 & 2.82 \\
1984 & 0.04234 & 0.01413 & 3.00 \\
1985 & 0.04029 & 0.01393 & 2.89 \\
1986 & 0.04479 & 0.01549 & 2.89 \\
1987 & 0.04754 & 0.01709 & 2.78 \\
1988 & 0.05070 & 0.01722 & 2.94 \\
1989 & 0.04957 & 0.01754 & 2.83 \\
1990 & 0.04767 & 0.01709 & 2.79 \\
1991 & 0.04786 & 0.01676 & 2.85 \\
1992 & 0.04638 & 0.01594 & 2.91 \\
\hline
\end{tabular}


Table 2. Age specific mortality rates of motor vehicle crashes for men in Taiwan $\left(\times 10^{5}\right)$

\begin{tabular}{lrrrr}
\hline & $1974-78$ & $1979-83$ & $1984-88$ & $1989-92$ \\
\hline $0-4$ & 11.15625 & 14.62999 & 13.96684 & 10.62087 \\
$5-9$ & 6.20706 & 7.83456 & 8.81291 & 8.02751 \\
$10-14$ & 5.76439 & 7.45063 & 7.86647 & 10.06480 \\
$15-19$ & 39.28931 & 53.80432 & 62.88582 & 65.82200 \\
$20-24$ & 49.04524 & 57.24284 & 59.83514 & 63.71538 \\
$25-29$ & 53.90111 & 57.03245 & 57.29534 & 57.07440 \\
$30-34$ & 46.58564 & 50.88671 & 47.28720 & 51.27617 \\
$35-39$ & 48.62938 & 54.79954 & 50.12539 & 44.71633 \\
$40-44$ & 46.66140 & 61.39948 & 58.39699 & 50.66384 \\
$45-49$ & 46.15804 & 62.57072 & 63.66942 & 67.44781 \\
$50-54$ & 47.12606 & 65.72524 & 73.50488 & 75.91415 \\
$55-59$ & 55.26906 & 71.04169 & 79.70158 & 81.69232 \\
$60-64$ & 55.27115 & 78.85395 & 88.96126 & 105.9312 \\
$65-69$ & 71.09650 & 92.69369 & 103.8099 & 120.4823 \\
$70+$ & 85.34780 & 124.1640 & 132.8734 & 150.5200 \\
\hline
\end{tabular}

of mortality rates of motor vehicle crashes at the same age are increasing generation by generation. However, the mortality rates at the same age for males leveled off during the birth cohorts of 1939-1958. For females, the tendency also shows an increase at the same age in different cohorts except that the mortality rates of the 35-39 and 40-44 age groups show a lower growth than other age groups. The above analysis, however, does not consider the three effects (age, period and cohort) simultaneously.

Tables 4 and 5 present the results of the parameter estimates and the goodness-of-fit statistics for the three submodels of AP, AC and PC, as well as for the full APC model under the constraint of Osmond and Gardner. Note that the goodness-of-fit statistic for males indicates a poor fit to the data (deviance $=$ 263.6, $d f=26$ ). However, this lack of fit is not an uncommon phenomenon especially when dealing with rates in large populations (Holford 1983) and may not necessarily imply a systematic departure from the model.

Table 3. Age specific mortality rates of motor vehicle crashes for women in Taiwan $\left(\times 10^{5}\right)$

\begin{tabular}{crrrr}
\hline & $1974-78$ & $1979-83$ & $1984-88$ & $1989-92$ \\
\hline $0-4$ & 9.46175 & 12.30534 & 11.80914 & 10.43463 \\
$5-9$ & 4.36794 & 5.57280 & 6.19069 & 6.28152 \\
$10-14$ & 3.81819 & 4.42034 & 4.91682 & 6.56416 \\
$15-19$ & 8.22902 & 11.95418 & 14.38956 & 19.77922 \\
$20-24$ & 9.05194 & 11.45795 & 14.08712 & 14.14984 \\
$25-29$ & 6.36719 & 8.81440 & 10.80390 & 11.56666 \\
$30-34$ & 7.28707 & 10.93375 & 11.83132 & 10.13574 \\
$35-39$ & 11.26316 & 12.84404 & 15.11529 & 14.66743 \\
$40-44$ & 14.42510 & 17.53943 & 16.94271 & 19.62238 \\
$45-49$ & 12.64268 & 20.04771 & 21.96099 & 23.60772 \\
$50-54$ & 16.44688 & 23.39047 & 24.18712 & 24.04362 \\
$55-59$ & 19.82164 & 28.35207 & 32.70885 & 28.49073 \\
$60-64$ & 25.02411 & 37.98584 & 33.73180 & 37.12000 \\
$65-69$ & 29.04300 & 40.56790 & 41.95628 & 47.91607 \\
$70+$ & 30.68891 & 47.65688 & 50.1299 & 54.78627 \\
\hline
\end{tabular}

Figure 2 shows the logarithm of relative mortality risks from motor vehicle crashes in different age groups in males and females (i.e. the age effect) as derived from the APC model. Except for the downward risk in age groups $5-9$ and $10-14$, the effect due to age depicts an increasing trend when it is adjusted for period and cohort effects. Similar to the findings in Tables 2 and 3 , there is an early peak of risk in age group 20-24 for both sexes, especially in males. The most risky group (beyond 70 years old) have 27.1 and 16.3 times the risk of the least risky groups (5-9 years old, 10-14 years old) for males and females respectively.

Figure 3 shows the period effect. There is a nearly linear trend in females as the period moved from 1974-1978 to 1989-1992. In males, the mortality rates increased from 1974-1978 to 1984-1988, and then leveled off during the last period.

The cohort effect is revealed in Fig. 4. In males, the risk of death from motor vehicle crashes increases in the early birth cohorts, reaches a peak around the birth cohort of 1931, and then decreases until the birth cohort of 1961. Afterward, the risk increases again until the cohort of 1981. After 1986, the risk goes down again. The risk of mortality of the 1981 cohort is 2.22 times of that of 1906 cohort. In females, the risk steadily increases until the birth cohort of 1966, then the risk increases sharply. The risk goes down from the 1986 cohort concurring with the males.

\section{DISCUSSION}

Studies on secular trends of mortality rates for an event can provide clues for epidemiologists to identify the risk factors. The three time variables involved in such an analysis are age, period (calendar year of death) and cohort (calendar year of birth). Cohort analysis was first employed by Frost in his study on tuberculosis mortality (Frost 1939). The technique was adopted and modified in subsequent investigations (Poskanzer and Schwab 1963; Susser and Stein 1962; Yates 1964). However, the method remained largely a graphic approach and usually considered at most two time variables. On the other hand, statistical APC analysis is able to independently quantify the effects due to age, period and cohort variables in a model if suitable constraints are imposed upon the parameters (Clayton and Schifflers 1987). This makes it worthwhile for us to adopt the method to detect different temporal trends early. Although it has been more widely used in chronic diseases such as cancer and tuberculosis, we have found that it is also useful in recognizing the global temporal changes of injuries reflecting the social and cultural alterations in rapidly industrializing countries 
(A)

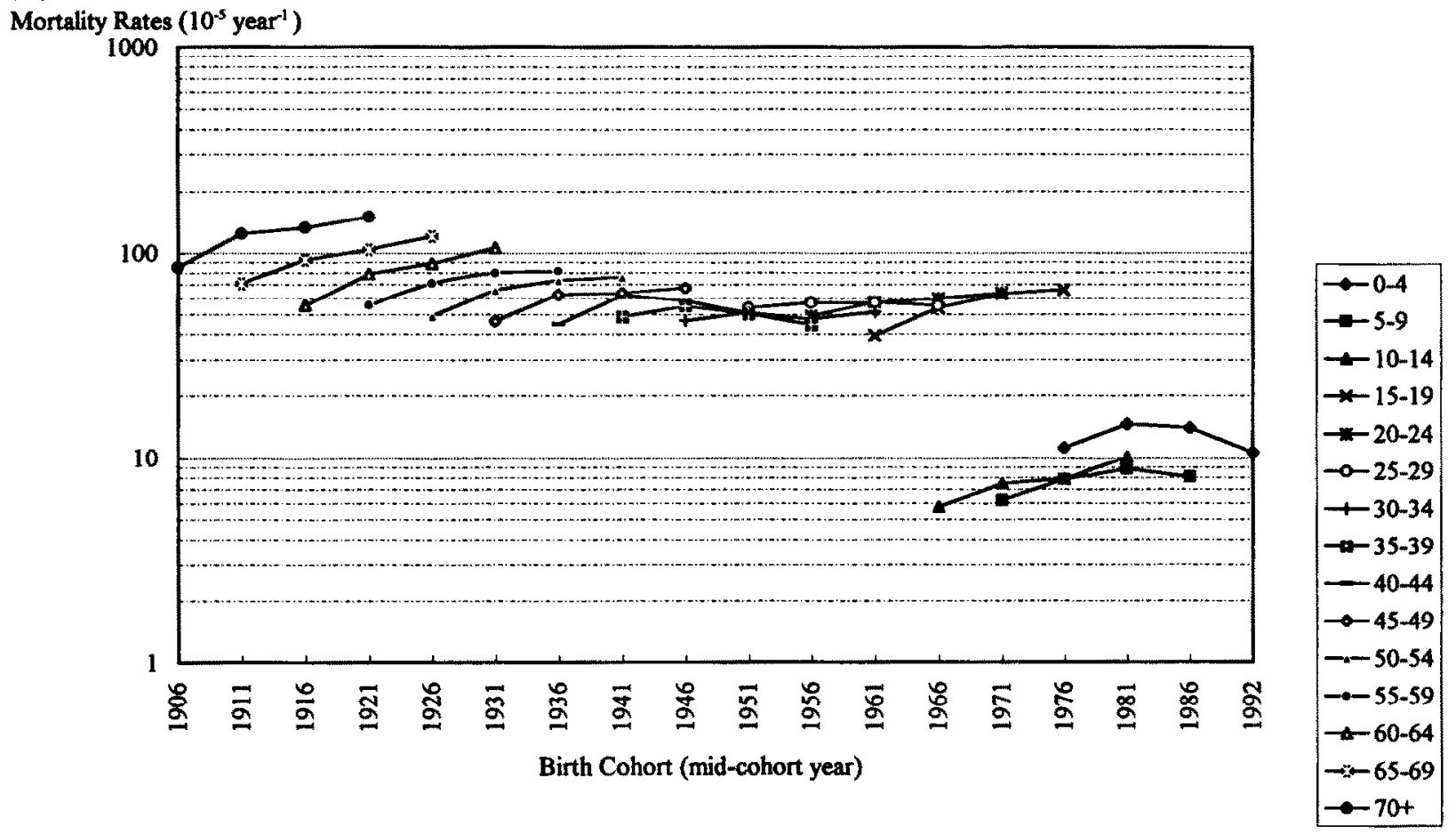

(B)

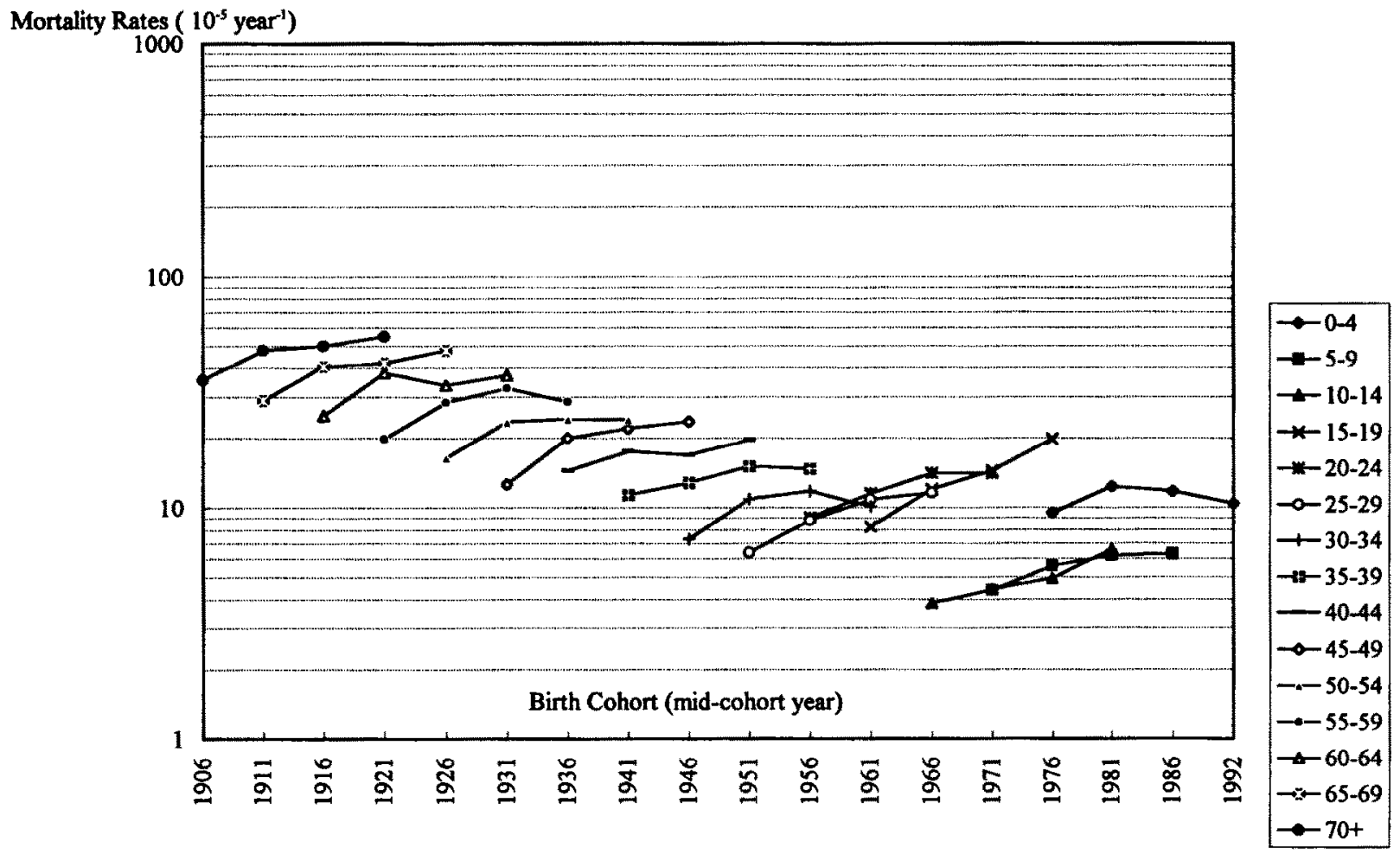

Fig. 1. (A)The age specific mortality rates by different birth cohorts for males in Taiwan. (B) The age specific mortality rates by different birth cohorts for females in Taiwan. 
such as Taiwan. Such changes may not easily be identified in the usual epidemiologic studies which are generally geared toward exploring spccific etiologic agents, e.g. vehicle types, use of safety belts or helmets, individual alcohol drinking behavior etc. However, these specific risk factors cannot be analyzed in the APC model, which is the limitation of using the methodology. Therefore, this study should be viewed both as a hypothesis-generating exercise and a documentation of socio-epidemiological trends, and it should be considered complementary to other more specific causal research for injury control.

Indices used to measure the impact of motor vehicle crashes included mortality per passenger mile, per vehicle mile and per head of population (Waller 1985). Epidemiologists usually consider a mortality rate as a special type of incidence rate which is

Table 4. Parameter estimates and goodness-of-fit statistics for the three submodels of AP, AC and PC as well as the full APC model under the constraint of Osmond and Gardner, males

\begin{tabular}{|c|c|c|c|c|}
\hline \multirow[b]{2}{*}{ Parameter estimates } & \multicolumn{4}{|c|}{ Models } \\
\hline & AP & $\mathrm{AC}$ & $\mathbf{P C}$ & APC \\
\hline \multirow{16}{*}{$\begin{array}{l}\text { Grand mean }(\mu) \\
\text { Age parameters }\left(\alpha_{i}\right)\end{array}$} & -7.7128 & -7.7579 & -7.7083 & -7.7554 \\
\hline & -1.2651 & -1.7844 & & -1.3718 \\
\hline & -1.7722 & -2.2781 & & -1.9074 \\
\hline & -1.7531 & -2.1662 & & -1.8476 \\
\hline & 0.2052 & -0.0500 & & 0.2016 \\
\hline & 0.2408 & 0.0911 & & 0.2952 \\
\hline & 0.2075 & 0.1404 & & 0.2764 \\
\hline & 0.0594 & 0.0248 & & 0.0899 \\
\hline & 0.0572 & 0.0113 & & 0.0139 \\
\hline & 0.1722 & 0.1357 & & 0.0658 \\
\hline & 0.2844 & 0.2300 & & 0.0972 \\
\hline & 0.3757 & 0.4423 & & 0.2367 \\
\hline & 0.7394 & 1.0249 & & 0.7759 \\
\hline & 0.6271 & 0.9514 & & 0.6402 \\
\hline & 0.7894 & 1.4083 & & 1.0462 \\
\hline & 1.0321 & 1.8184 & & 1.3879 \\
\hline \multirow{4}{*}{ Period parameters $\left(\beta_{j}\right)$} & -0.2151 & & -0.4479 & -0.2515 \\
\hline & 0.0064 & & -0.0599 & -0.0049 \\
\hline & 0.1174 & & 0.2049 & 0.1453 \\
\hline & 0.0913 & & 0.3029 & 0.1111 \\
\hline \multirow[t]{18}{*}{ Cohort parameters $\left(\gamma_{k}\right)$} & & -1.1267 & 1.0900 & -0.5228 \\
\hline & & -0.7968 & 1.0249 & -0.3499 \\
\hline & & -0.6730 & 0.8108 & -0.3268 \\
\hline & & -0.5478 & 0.7562 & -0.1985 \\
\hline & & -0.3653 & 0.5544 & -0.0933 \\
\hline & & 0.1231 & 0.7056 & 0.3602 \\
\hline & & -0.0780 & 0.3497 & 0.0873 \\
\hline & & 0.1614 & 0.2919 & 0.2592 \\
\hline & & 0.1793 & 0.1980 & 0.2088 \\
\hline & & 0.1050 & 0.1000 & 0.0708 \\
\hline & & 0.0792 & 0.0620 & -0.0280 \\
\hline & & 0.1277 & 0.0954 & -0.0474 \\
\hline & & 0.2209 & -0.0581 & -0.0340 \\
\hline & & 0.3716 & -0.2901 & 0.0685 \\
\hline & & 0.4844 & -0.7109 & 0.1782 \\
\hline & & 0.7113 & -1.5543 & 0.2826 \\
\hline & & 0.6315 & -1.6809 & 0.1436 \\
\hline & & 0.3922 & -1.7447 & -0.0586 \\
\hline Deviance & 490.8 & 345.4 & 2328.8 & 263.6 \\
\hline Degree of freedom & 42 & 28 & 39 & 26 \\
\hline
\end{tabular}

Table 5. Parameter estimates and goodness-of-fit statistics for the three submodels of AP, AC and PC as well as the full APC model under the constraint of Osmond and Gardner, females

\begin{tabular}{|c|c|c|c|c|}
\hline \multirow[b]{2}{*}{ Parameter estimates } & \multicolumn{4}{|c|}{ Models } \\
\hline & AP & $\mathrm{AC}$ & $\mathrm{PC}$ & APC \\
\hline \multirow{16}{*}{$\begin{array}{l}\text { Grand mean }(\mu) \\
\text { Age parameters }\left(\alpha_{i}\right)\end{array}$} & -8.7812 & -8.7846 & -8.7257 & -8.7845 \\
\hline & -0.3395 & -1.3027 & & -0.7009 \\
\hline & -1.0227 & -1.9067 & & -1.3834 \\
\hline & -1.1477 & -1.8967 & & -1.4523 \\
\hline & -0.1427 & -0.6691 & & -0.3280 \\
\hline & -0.2460 & -0.5676 & & -0.3064 \\
\hline & -0.4964 & -0.6689 & & -0.4955 \\
\hline & -0.4486 & -0.4640 & & -0.3857 \\
\hline & -0.1561 & -0.0843 & & -0.0837 \\
\hline & 0.0900 & 0.2678 & & 0.1820 \\
\hline & 0.2318 & 0.5231 & & 0.3479 \\
\hline & 0.3402 & 0.7305 & & 0.4699 \\
\hline & 0.5571 & 1.0614 & & 0.7115 \\
\hline & 0.7530 & 1.3609 & & 0.9301 \\
\hline & 0.9421 & 1.6632 & & 1.1517 \\
\hline & 1.0854 & 1.9530 & & 1.3428 \\
\hline \multirow[t]{4}{*}{ Period parameters $\left(\beta_{j}\right)$} & -0.2935 & & -0.4732 & -0.3454 \\
\hline & 0.0217 & & -0.0346 & -0.0063 \\
\hline & 0.1086 & & 0.1700 & 0.1274 \\
\hline & 0.1632 & & 0.3378 & 0.2243 \\
\hline \multirow[t]{18}{*}{ Cohort parameters $\left(\gamma_{k}\right)$} & & -1.2575 & 1.1099 & -0.4290 \\
\hline & & -0.8749 & 1.0964 & -0.2564 \\
\hline & & -0.7661 & 0.9467 & -0.2309 \\
\hline & & -0.6481 & 0.8357 & -0.1660 \\
\hline & & -0.5385 & 0.6185 & -0.1561 \\
\hline & & -0.4233 & 0.4432 & -0.1223 \\
\hline & & -0.3339 & 0.2517 & -0.1190 \\
\hline & & -0.2032 & 0.0984 & -0.0787 \\
\hline & & -0.1368 & -0.1129 & -0.0978 \\
\hline & & 0.0091 & -0.2661 & -0.0348 \\
\hline & & 0.0980 & -0.4233 & -0.0270 \\
\hline & & 0.1790 & -0.5096 & -0.0371 \\
\hline & & 0.4440 & -0.4888 & 0.1197 \\
\hline & & 0.5711 & -0.5973 & 0.1786 \\
\hline & & 0.8742 & -0.5388 & 0.4180 \\
\hline & & 1.0540 & -0.8379 & 0.4487 \\
\hline & & 1.0335 & -0.8459 & 03699 \\
\hline & & 0.9195 & -0.7799 & 0.2230 \\
\hline Deviance & 38.0 & 33.6 & 281.3 & 17.6 \\
\hline Degree of freedom & 42 & 28 & 39 & 26 \\
\hline
\end{tabular}

computed from the number of cases who died in the numerator and total person-time at risk in the denominator (Rothman 1986). The denominator of the mortality rate of motor vehicle crashes is not so accurately quantified as passenger mile or the total consumption of gasoline from survey data because of frequent traffic jams in Taiwan. So, mortality per head of population was used in our study (Department of Health 1994). Since there has been no major change in the coding criteria among nosologists in Taiwan for the death certificates of motor vehicle crashes during the last decades, we believe that the numerators of the mortality rates remained comparable across the years. Since the total number of registered motor vehicles increased from 957,295 (1971) to $15,190,089$ (1993) (Department of Statistics, 


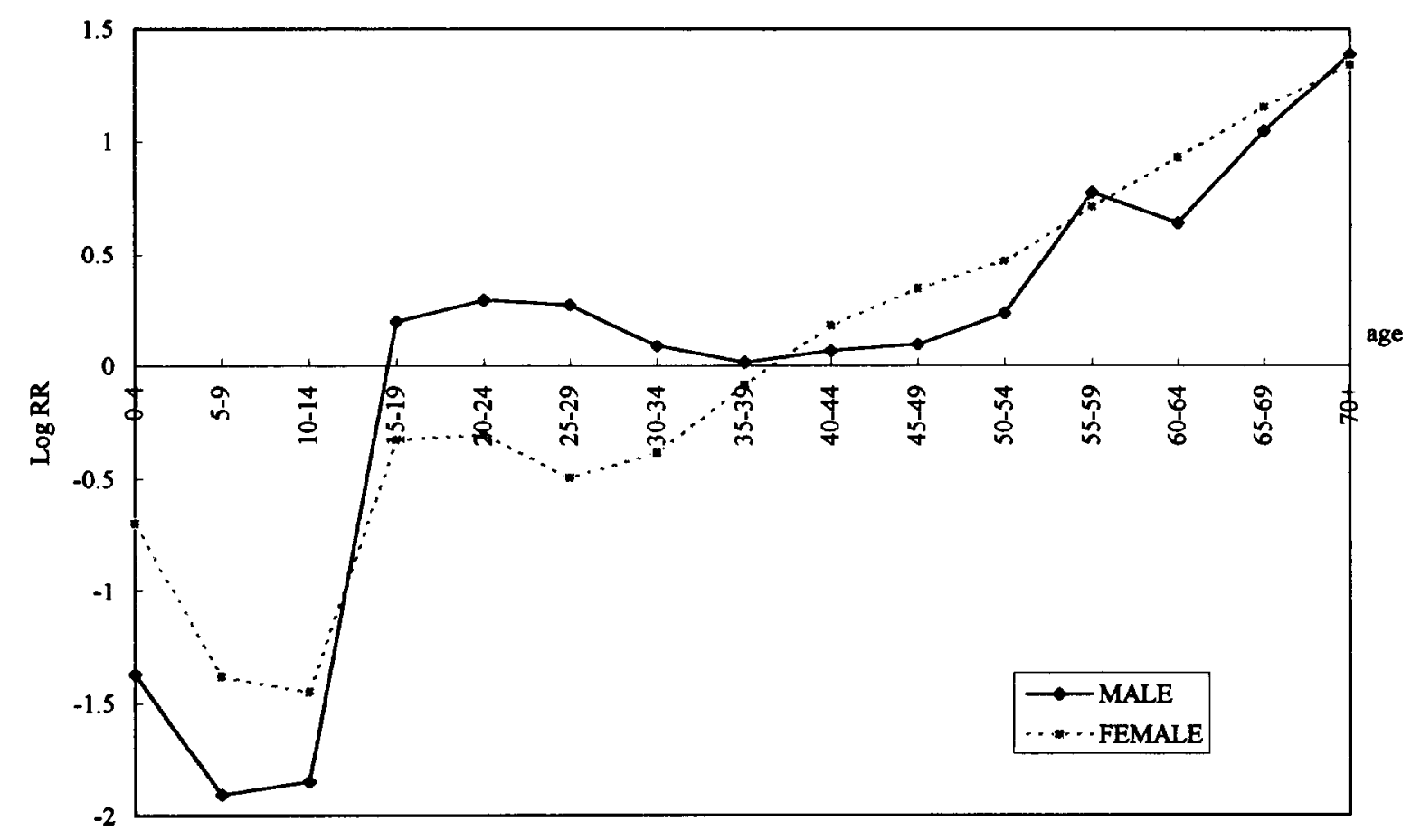

Fig. 2. Age effect on motor vehicle mortality from 1974 to 1992 in Taiwan by sex.

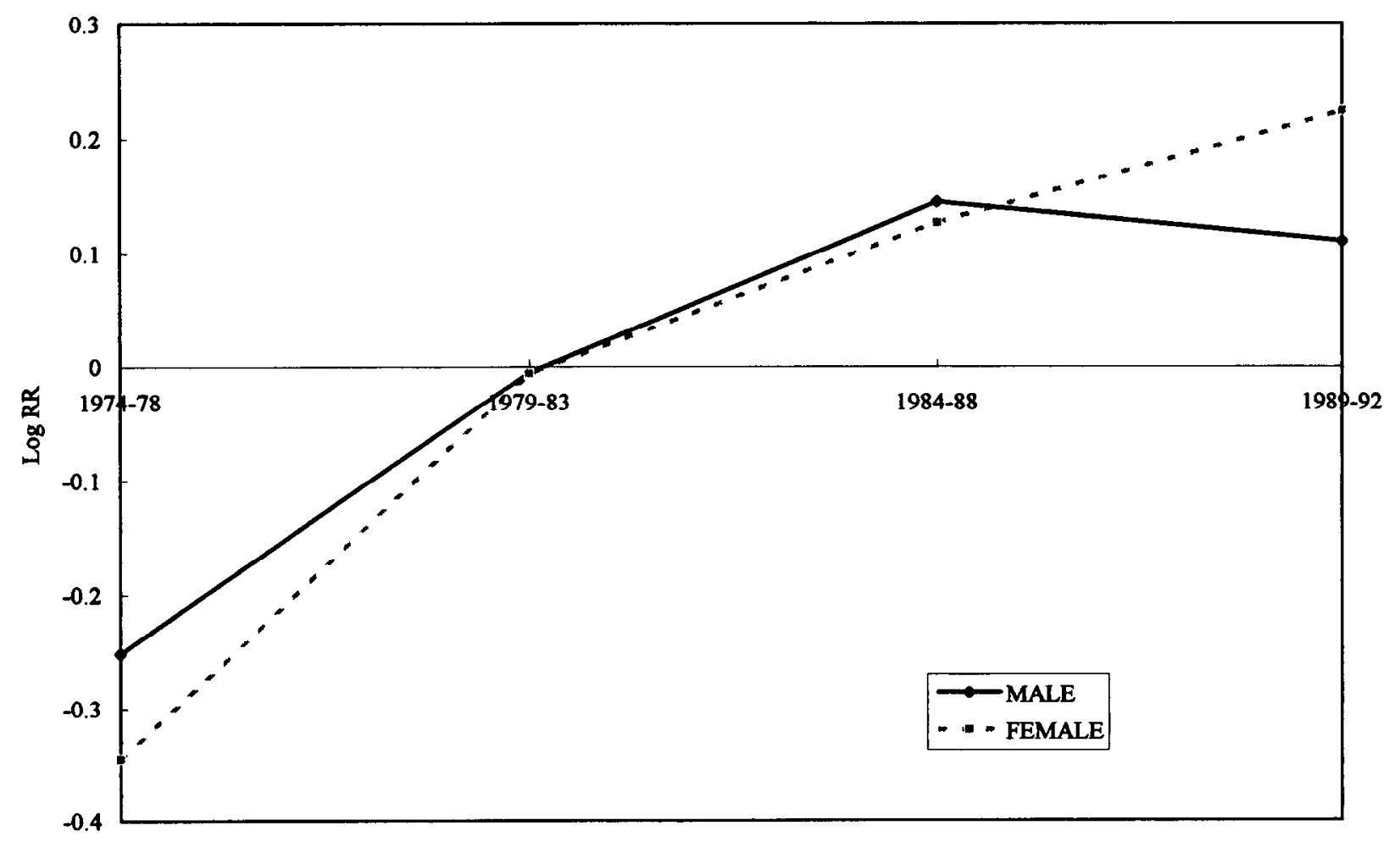

Fig. 3. Period effect on motor vehicle mortality from 1974 to 1992 in Taiwan by sex. 


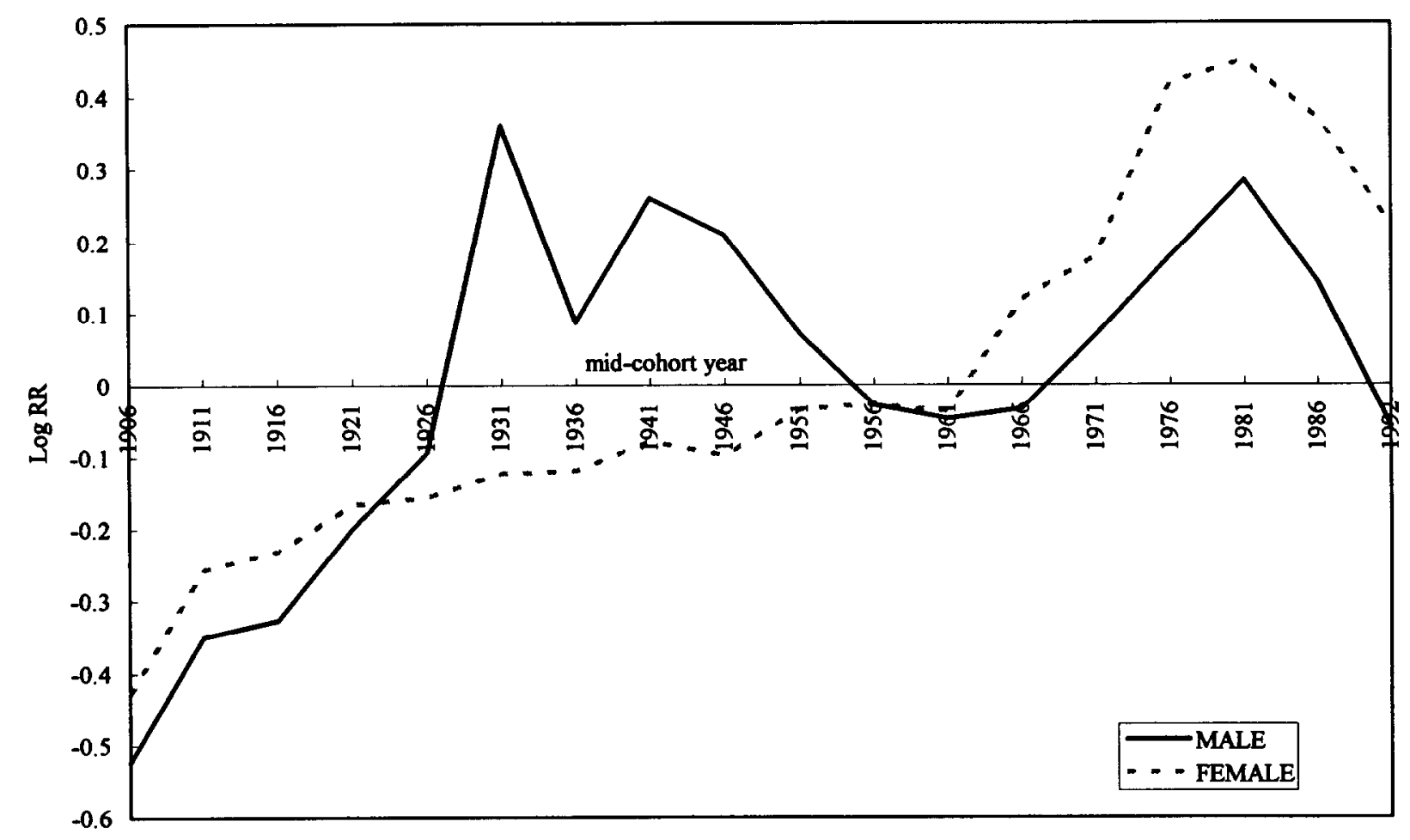

Fig. 4. Cohort effect on motor vehicle mortality from 1974 to 1992 in Taiwan by sex.

Ministry of Transportation and Communications 1994) during the last 2 decades, the number of riders and their person-time at risk spent on the road have increased accordingly. Moreover, Taiwan is a small island with a population density of 587 person $/ \mathrm{km}^{2}$ (Department of Health 1994). The rapidly increasing number of cars generally aggravate traffic jams in metropolitan areas and highways, which further increased the population-time at risk. Thus, we expect the population-time at risk (the denominator) to increase by a factor of more than 15 during 1971-93 and the mortality rate should decrease if the occurrence of mortality due to motor vehicle crashes generally stayed constant. Nonetheless, we have observed a consistent increase in both cumulative mortality rates (Table 1) and period effect during 1974-92 (Fig. 3). So, we conclude that mortality due to motor vehicle crashes has become more serious in Taiwan during the last 2 decades.

Our analysis of the trend of motor vehicle mortality data in Taiwan between 1974 to 1992 by means of the APC model revealed that age is a significant variable in the three time variables. After an adjustment for period and cohort effect, subjects aged between 15 and 29 or beyond 54 years old are at a higher risk (Fig. 2). This effect in males aged between 15 and 29 is more prominant than in females because there are many more male motorcycle riders than female. The younger age groups usually ride a motorcycle without any helmet protection which easily leads to head injuries and severe trauma. Wearing a full coverage helmet produces an estimated $64-74 \%$ reduction of risk of head injury for helmeted riders compared with those unhelmeted. A full helmet and partial coverage helmet might produce an cstimated 0-28\% reduction of risk of head injury (Tsai et al. 1996). In Taiwan, the proportion of those wearing a helmet in fatalities for motor cyclists over 60 years is $28 \%$ in contrast to less than $10 \%$ for fatalities among motor cyclists younger than 20 years. However, the fatality rate of those older than 60 years is still higher than that of the younger group (Ding et al. 1994a; Evans 1988). In addition to motorcycle riders, pedestrians are also the major victims of motor vehicle crashes. Older people also have a higher fatality rate than younger ones (Ding et al. 1994b). Since 56\% of fatalities among older people in traffic accidents in Taiwan were pedestrians (Ding et al. 1994a), we also need to improve pedestrian safety in the future to prevent such tragedies (Chiu et al. 1995).

To our surprise, the period effect of motor vehicle mortality for females is still increasing in more recent periods, despite the fact that medical care and equipment for mechanical protection such as safety belts are improving. The fact that the absolute number of female riders is increasing and that risky behavior 
while driving (such as alcohol consumption) is becoming more prevalent (Wu et al. 1991) in recent years may be the major reasons for this increasing trend. It is speculated that the dramatically increasing risk since the 1959-1963 cohort for both sexes may be due to the increasing popularity of riding motorcycles in the younger generations. Also, since the most risky cohort (1979-1983) remains younger than 14 years old in the study periods, a possible mechanism of the high cohort effect could be that recently teenagers are riding motorcycles earlier in their lives. If these hypotheses are true, legislation for a minimum age for riding motorcycles and enforcement of safety helmet laws are urgent needs (Chiu 1995).

In summary, our analysis, in presenting separate effects due to the age, period and cohort variables, has shown that there is an increasing trend of motor vehicle mortality in Taiwan during the last two decades. The findings also suggest that the younger cohorts have greater risks of motor vehicle injuries than their parents. This issue deserves attention to prevent increasing mortality in the future.

\section{REFERENCES}

Baker, S. P.; O'Neill, B.; Ginsburg, M. J.; Li, G. The injury fact book, 2nd ed. Oxford: Oxford University Press, 1992.

Bangdiwala S. I.; Anzola-Perez E.; Romer C.; Schmidt B. et al. The incidence of injuries in young people: I. Methodology and results of a collaborative study in Brazil, Chile, Cuba and Venezuela. Int. J. Epidemiol. 19: 115-124; 1990.

Chen L. H.; Lin M. R.; Wang J. D. The mortality rate, years of potential life lost and its monetary value of death caused by motor vehicle accidents. J. Natl. Public Health Assoc. (ROC) 12: 368-379; 1993.

Chiu W. T. The motorcycle helmet law in Taiwan. JAMA 274: 941-942; 1995.

Chiu W. T.; Hung C. C.; Shih C. J. Epidemiology of head injury in rural Taiwan - a four years survey. J. Clin. Neurosci. 2: 210-215; 1995.

Clayton D.; Schifflers E. Models for temporal variation in cancer rates, II: age-period-cohort models. Stat. Med. 6: 469-481; 1987.

Department of Health, Executive Yuan, Republic of China: Health Statistics 1974-1992, 1994. Taipei: Department of Health 1974 1974-1992; 1994.

Department of Statistics, Ministry of Transportation and Communications: Monthly Statistics of Transportation and Communications, Republic of China, Jan 1994. Taipei: Department of Statistics, Ministry of Transportation and Communications; 1994.

Ding S. L.; Pai L.; Wang J. D.; Chen K. T. Head injuries in traffic accidents with emphasis on the comparisons between motorcycle-helmet users and non users. Chinese J. Formos. Med. Assoc. 93: S42-48; 1994.

Ding S. L.; Wang J. D.; Chen K. T. Epidemiologic analysis of 845 cases of pedestrian traffic injuries. Chin. Med. J. (Taipei) 53: (Suppl. B): 16-22; 1994.

Evans L. Risk of fatality from physical trauma versus sex and age. J. Trauma 28: 368-378; 1988.
Evans L. How safe were today's older drivers when they were younger?. Am. J. Epidemiol. 137; 769-775; 1993.

Frost W. H. The age selection of mortality from tuberculosis in successive decades. Am. J. Hyg. Soc. A. 30: 91-96; 1939.

Grisso J. A.; Wishner A. R.; Schwarz D. F.; Weene B. A. et al. A population-based study of injuries in inner-city women. Am. J. Epidemiol. 134: 59-68; 1991.

Holford T. R. The estimation of age, period and cohort effects for vital rates. Biometrics 39: 311-324; 1983.

Holford T. R. Understanding the effects of age, period and cohort on incidence and mortality rates. Ann. Rev. Publ. Health 12: 425-457; 1991.

Langley J. D.; McLoughlin E. Injury mortality and morbidity in New Zealand. Accid. Anal. Prev. 21: $243-254 ; 1989$.

Lee L. T.; Lee W. C.; Lin R. S.; Chen S. C. Age-periodcohort analysis of lung cancer mortality in Taiwan 1966-1990. Anticancer Res. 14: 673-676; 1994.

Lee L. T.; Chen C. J.; Lee W. C.; Luh K. T.; Hsieh W. C.; Lin R. S. Age-period-cohort analysis of pulmonary tuberculosis mortality in Taiwan 1961-1990. J. Formos. Med. Assoc. 93: 657-662; 1994.

Lee W. C.; Lin R. S. Analysis of cancer rates using excess risk age-period-cohort models. Int. J. Epidemiol. 24: 671-677; 1995.

Lee W. C.; Lin R. S. Autoregressive age-period cohort models. Stat. Med. 15: 273-281; 1996.

Lee, W. C.; Lin, R. S. Modeling the age-period-cohort trend surface. Biom. J.; 1996 (in press).

Li G.; Baker S. P. A comparison of injury death rates in China and the United States, 1986 1986. Am. J. Public Health 81: 605-609; 1991.

Osmond C.; Gardner M. J. Age, period and cohort models applied to cancer mortality rates. Stat. Med. 1: $245-259 ; 1982$.

Poskanzer D. C,; Schwab R. S. Cohort analysis of Parkinson's syndrome: evidence of a single etiology related to subclinical infection about 1920 . J. Chron. Dis. 16: $961-973 ; 1963$.

Rockett I. R. H.; Smith G. S. Homicide, suicide, motor vehicle crash, and fall mortality: United States' experience in comparative perspective. Am. J. Public Health 79: 1396-1400; 1989.

Rothman, K. J. Modern epidemiology, 1st ed. Boston, MA: Little, Brown, and Company; 1986.

SAS Institute Inc: SAS/IML, user's guide, release 6.03 ed. Cary NC, USA: SAS Institute Inc.; 1988.

Susser M.; Stein Z. Civilization and peptic ulcer. Lancet 1: $24-35 ; 1962$.

Tsai Y. J.; Wang J. D.; Huang W. F.: A case-control study on the effectiveness of prevention of head injuries by helmet among motorcycle riders in Taipei. Am. J. Epidemiol. 142: 974-981; 1996.

Waller J. A. Injury control: a guide to the causes and prevention of trauma, 1st ed. Lexington, MA / Toronto: D.C. Heath and Company; 1985.

World Health Organization: Manual of the international statistical classification of diseases, injuries, and causes of death, 9th revision. Geneva, 1: 554-8; 1975.

Wu S. I.; Yang G. Y.; Chou P.; Chao S. H.; Tao C. C.; Chen K. T. An analysis of traffic injuries in Taiwan in relation to alcohol use and economic loss. Injury 22: 357-361; 1991.

Yates P. O. A change in the pattern of cerebrovascular disease. Lancet 5: 65-69; 1964. 